Global Conferences Series:

Social Sciences, Education and Humanities (GCSSSEH), Volume 6, 2020

International Conference Fakultas Tarbiyah dan Keguruan Universitas Islam Negeri Imam Bonjol Padang (ICFTKUINIBP) 2020

DOI: https://doi.org/10.32698/icftk398

\title{
Readiness and Job Prospects of English Tadris Students: A Form of Application and Objectives for Independent Learning
}

\section{Kesiapan dan Prospek Kerja Mahasiswa Tadris Bahasa Inggris: Wujud Penerapan dan Tujuan Merdeka Belajar}

\author{
Hidayat Al Azmi ${ }^{a}$, Zulvia Trinova ${ }^{\text {a }}$, Hadeli, Elismawati ${ }^{a}$ \\ ${ }^{a}$ Universitas Islam Negeri Imam Bonjol, Padang, Indonesia \\ Email: marvelouse_80@yahoo.co.id
}

\begin{abstract}
Abstrak: Salah satu tujuan dari Merdeka balajar dalam perguruang tingga adalah melahirkan lulusan yang memiliki daya saing dalam skala Internasional. Tadris Bahasa Inggris Fakultas Tarbiyah UIN Imam Bonjol Padang merupakan Program Studi yang diharapkan mampu melahirkan tamatan yang memiliki kopetisi global dan kreativitas untuk bersaing didunia kerja setelah menamatkan pendidikan. Dengan adanya pencanangan Merdeka Belajar oleh mentri Pendidikan dan Kebudayaan, sebagai respon perkembangan zaman yang sudah diwarnai oleh perkembangaan teknologi dalam bentuk digitalisasi, maka perubahan permintaan dan kebutuhan masyarakat akan lulusan Tadris Bahasa Inggris juga berkembang. Tidak hanya untuk menjadi guru dikelas para tamatan Program Studi ini diharapkan mampu menjadi para professional d pada bidang pengajaran bahasa Inggris dengan memanfaatkan ketersediaan teknologi dan sumberdaya lainnya seperti menjadi erterpreneur pembelajaran bahasa Inggris Online, kursus Online, ELT Aplication Creator dan lain - lain. Untuk merespon hal ini maka pihak Program Studi disamping mampu menciptakan program dan mengadakan penyesuaian terhahadap kurikulum yang dipakai pihak Prodi juga diharapkan mampu merespon Kebijakan Merdeka Belajar sehingga mampu meningkatkan kompetensi yang dimiliki oleh calon lulusan. Untuk itu, perlu adanya kajian yang membahas tentang Kesiapan dan Prospek Kerja Mahasiswa Tadris Bahasa Fakultas Tarbiyah dan Keguruan UIN Imam Bonjol Padang.
\end{abstract}

Key words: Kesiapan, prospek kerja, merdeka belajar

\section{PENDAHULUAN}

Pendidikan tinggi di Indonesia memilik fungsi untuk Mengembangkan kemampuan dan membentuk watak serta peradaban bangsa yang bermartabat dalam rangka mencerdaskan kehidupan bangsa, Mengembangkan Sivitas Akademika yang inovatif, responsif, kreatif, terampil, berdaya saing, dan kooperatif melalui pelaksanaan Tridharma, serta mengembangkan Ilmu Pengetahuan dan Teknologi dengan memperhatikan dan menerapkan nilai Humaniora (UU No. 12 Tahun 2012 Pasal 4). Selain memiliki fungsi pendidikan tingg di Indonesia juga memiliki tujuan untuk Berkembangnya potensi Mahasiswa agar menjadi manusia yang beriman dan bertakwa kepada Tuhan Yang Maha Esa dan berakhlak mulia, sehat, berilmu, cakap, kreatif, mandiri, terampil, kompeten, dan berbudaya untuk kepentingan bangsa. Dihasilkannya lulusan yang menguasai cabang Ilmu Pengetahuan dan/atau Teknologi untuk memenuhi kepentingan nasional dan peningkatan daya saing bangsa. Dihasilkannya Ilmu Pengetahuan dan Teknologi melalui Penelitian yang memperhatikan dan menerapkan nilai Humaniora agar bermanfaat bagi kemajuan bangsa, serta kemajuan peradaban dan kesejahteraan umat manusia. Terwujudnya Pengabdian kepada Masyarakat berbasis penalaran dan karya Penelitian yang bermanfaat dalam memajukan kesejahteraan umum dan mencerdaskan kehidupan bangsa. Dengan merespon perkembangan zaman dimana dunia telah mengalami perubahan yang signifikan dalam dalam bidang sosial dimana dunia industri modern sangat menentukan kehidupan masyarakat dunia, serta berpedoman pada tujuan Pendidikan Tinggi maka Kementrian Pendidikan dan Kebudayaan telah 
menciptakan konsep Merdeka Belajar yang dianggap merupakan sebuah solusi dalam menjawab tangtanga tersebut.

Program studi Tadris Bahasa Inggris Fakutas Tarbiyah dan Keguruann UIn Imam Bonjol Padang sebagai prodi lulusan yang bisa berkiprah di masyarakat luas dapat berperan aktif dalam mewujudkan merdeka belajar yang sudah dicanangkan oleh Kementrian Pendidikan dan Kebudayaan Indonesia. Respon dari kebijakan ini dapat dituangkan kedalam bentuk pengkajian kesiapan prodi dan lulusan, merancang program magang dan mengadakan studi dan kajian tentang prospek kerja lulusan Dengan mempertimbangkan paparan diatas maka makalah ini dibuat untuk membahas kesiapan dan prospek kerja mahasiswa tadris bahasa inggris sebagai respon kebijakan Merdeka Belajar.

\section{BELAJAR MANDIRI DAN MERDEKA BELAJAR}

Belajar Mandiri merupakan pendekatan yang biasanya berlangsung pada pembelajaran pada perguruan tinggi yang mengandalkan kemampuan berfikir kritis, belajar mandiri yang berarti cara berbeda pada masing masing siswa, disiplin ilmu serta budaya. Merdeka belajar juga dimaknai sebagai proses belajar sebagai sebuah proses belajar, sebuah metode dan filosopi dalam pendidikan diman siswa mendapatkan ilmu pengetahuan dengan upaya mereka sendiri serta menngembangkan kemampuan serta evaluasi kritis yang mencakup kebebasan dalam memilih tujuan belajar yangberada dibawah ketentuan Penasehat akademik. Fisher dalam Wiliam (2003) menjelaskan bahwa Siswa Mandiri dapat menentukan pilihan mereka dengan tanggung jawab yang mereka miliki pada saat dia ingin belajar atau ingin memppelajari materi yang dia pilih. Adapun pringsi dari belajar mandiri itu sendiri menciptakan kemampuan kemandirian sedini mungkin. Untuk itu guru harus bisa berperann sebagai fasilitator dan motovatoor agar siswa dapat menjadi mandiri berdasarkan cara belajar, keinginan dan bakat yang mere miliki (Fridani,2009). Pada sisi lain, konsep "Merdeka Belajar" merupakan alternative dalam menghadapi masalah dalam dunia pendidikan. Disamping itu guru mendapat keringan dalam melaksanakan tugas mereka sebagai pendidik dan diberikan kebebasan dalam mengajar dan memberikan penilaian dengan menggunakan format penilaian yang dipilih. Merdeka belajar juga merupakan upaya dalam merespon banyaknya kendala-kendala yang dihadapi oleh guru dan dosen dalam tugas (Kusumaryono dalam Yamin dan Syahrir , 2019). Program Merdeka Belajar Kampus Merdeka meliputi empat kebijakan utama yaitu: kemudahan pembukaan program studi baru, perubahan sistem akreditasi perguruan tinggi, kemudahan perguruan tinggi menjadi badan hukum, dan hak belajar tiga semester di luar program studi. Mahasiswa diberikan kebebasan mengambil SKS di luar program studi, tiga semester yang di maksud dapat diambil untuk pembelajaran di luar prodi dalam PT dan atau pembelajaran di Luar PT. Permendikbud Nomor 3 Tahun 2020 tentang Standar Nasional Pendidikan Tinggi : Perguruan Tinggi wajib memberikan hak bagi mahasiswa untuk secara sukarela (dapat diambil atau tidak): Dapat mengambil SKS di luar perguruan tinggi sebanyak 2 semester (setara dengan $40 \mathrm{sks}$ ). Ditambah lagi, dapat mengambil sks di prodi yang berbeda di PT yang sama sebanyak 1 semester (setara dengan 20 sks). -Saat ini pertukaran mahasiswa dengan full credit transfer sudah banyak dilakukan dengan mitra PT luar negeri, tetapi di dalam negeri sendiri masih sangat sedikit. Degan belajar lintas kampus (dalam dan luar negeri), tinggal bersama dengan keluarga di kampus tujuan, wawasan mahasiswa tentang ke-Bhinneka tunggal ika an akan kuat, persaudaraan lintas budaya dan suku akan semakin kuat.Kerjasama antar perguruan tinggi, konsorsim keilmuan, menyepakati untuk pertukaran mahasiswa dengan full credit transfer. PT dapat mengalokasikan quota untuk mahasiswa inbound atau sejumlah mahasiswa yang melakukan outbound (resiprokal).

\section{TADRIS BAHASA INGGRIS FAKULTAS TARBIYAH DAN KEGURUAN UIN IMAM BONJOL PADANG}

Program Studi Tadris Bahasa Inggris merupakan Program studi umum yang berada pada Fakustas Tarbiyah dan Keguruan UIN Imam Bonjol yang bertujuan untuk menghasilkan lulusan calon guru bahasa Inggris yang dapat bekerja pada tingkatan Madrasah Tsanawiyah dan Madrasah Aliyah. Tidak hauntuk menjadi guru bahasa Inggris lulusan Program Studi ini juga bisa bekerja sebagai penerjemah, karyawan pada perusaan swasta dan kantor pemerintah. Sebagai program studi yang berada pada perguruan tinggi negeri maka program studi ini diharapkan dapat mejadi program studi ungggulan Universitas karena memiliki sumberdaya dosen profesional yang yang mencukupi dan memiliki kompetensi global dengan penguasaan bahasa Asing yang dimiliki. Dengan adanya perubahan permintaan masyarakan akan lulusan perguruan tinggi, maka Prodi Tadri Bahasa Inggris diharapkan mampu meresponya dengan mengadakan penyesuaian terhadap Visi, Misi dan tujuan sehingga berdampak pada peningkatan kompetensi lulusan yang 
mampu merespen perkembangan zaman. Kurikulum Program Tadris Bahasa Inggris Fakultas Tarbiyah UIN Imam Bonjol Padang memiliki komponen Universitas, Fakultas dan Prodi. Berikut adalah sampel kurikulum yang dimaksud:

\begin{tabular}{lll}
\hline Komponen Universitas & Komponen Fakultas & Komponen Program Studi \\
\hline Pengantar Studi Al Qur an Hadist & Sejarah Pendidikan Islam & Basic Listening \\
Pengantar Hukum Islam & Psikologi Agama & Basic Reading \\
Pengantar Studi sejarah & Ilmu Pendidikan Islam & Advanced Listening \\
Peradaban Islam & PengemBanagn Kurikulum & Advanced English Grammar \\
Pancasila & Profesi Keguruan & General Speaking \\
Bahasa Indonesia & PPL & Introduction To Linguistic \\
Tafsir Tarbawi & Bahasa Inggris & Language Learning Strategies \\
Hadith Tarbawi & & Cross Cultural Understanding \\
& & Analysis of EFL Curriculum and \\
& & Text book for SMA \\
& & Academic Scientific Writing \\
\hline
\end{tabular}

Dari mata paparan mata kuliah pda table diatas, program Studi Tadris Bahasa Inggris memiliki mata kuliah komponen Universitas yang bertujuan untuk membekali mahasiswa dengan komptensi keagamaan sehingga mereka memiliki pengetahuan agama yang memadai sehingga dapat memenuhi kriteria apabila mereka ditempatkan pada sekolah atau madrasah yang berada dibawah Kementrian Agama Republik Indonesia. Disamping itu, kurikulum Programm studi ini juga memilikili komponen Fakultas yang pada umumnya memiliki isi keilmuan yang berkaitan dengan pendidikan KeIslaman dan Pendidikan Umum. Hal ini dimaksudkan agar lulusan Fakultas Tarbiyah dan Keguruan benar - benar memiliki kompetnsi dalam mendidik dan menyelenggarakan pendidikan. Kurikulum Tadris Bahasa Inggris juga memilik komponen Prodi yang berfokus pada skill bahasa Inggris dan pengajaran bahasa Inggris. Hal ini dimaksudkan agar mahasiswa benar memiliki kemampuan bahasa Inggris yang sudah memenuhi kriteria sebagai calon guru bahasa Inggris serta memiliki kompetensi dalam bidang pengajaran Bahasa Inggris sebagai bahasa asing. Dari gambaran diatas, maka dapat disimpulkan bahwa program studi belum memiliki mata kuliah yang dapat memberikan mahasiswa kompetensi dalam menjadikan mahsiswa memiliki alternative sebagaimana yang dimasud pada poin E. Dalam hal ini kompenen mata kuliah khusus Prodi seharusnya mencakup aspek teknologi hal poin lainya yangberkaitan dengan tantang dan permintaan masyarakat berkaitan dengan bahasa Inggris.

\section{PROSPEK KERJA PEALTERNATIF DAN UPAYA MAGANG LULUSAN TADRIS BAHASA INGGRIS}

Salahsatu tujuan utama dari sebuah progam studi adalah mengahasilkan lulusanyang memilik daya saing dan mampu bekerja sesuai dengan permintaan masyarakat luas. Tidak hanya menjadi guru bahasa Inggris barukut ini adalah beberapa alternatif pekerjaan yang dapat dipilih oleh para lulusa TBI pada era teknologi digital.

\section{ELT Content Creator}

LEiA, Language Education in Asia (2011) menyatakan aplikasi youtube merupakan media yang dapat dilihat dan didengar sehingga guru yang kreatif dapat dengan menggunakanya dalam upaya mengajarkan skill speaking dan listening. Untuk lulusan pendidikan bahasa Inggris menjadi pembuat mmateri ajar dengan menggunakann media youtube merupakan alternative profesi yang dapat mereka pilih. Profesi sangat membutuhkan kreatifitas yang bertujuan untuk membantu siswa dalam menguasai skill bahasa Inggris. Dalam upaya menerapkan mereka belajar, mahasiwa TBI dalap mengikuti magang atau pelatihan dalam membuat materi pembelajaran dengan menggunakan media seperti video kreatif yang berkaitan dengan pembelajaran bahasa Inggris. 


\section{Online Couse Manager}

Pada beberapa tahun terakhir, pembelajaran bahasa Inggris online telah berkembang dengan sangat cepatnya. Model pembelajaran ini mempekerjakan guru - guru tamatan jurusan pendidikan bahasa Inggris. Dengan dengan menggunakan berbagai macam aplikasi dan social media banyak dari alternative pekerjaan menjadi adang bisnis karena kemampuan bahasa inggris masih merupakan kebutuhan bagi sebagian masyarakat. Untuk menyikapi hal tersebut, maka diperlukan personer yang memiliki kemampuan manageman dalam lembaga pendidikan online. Hal ini bertujuan agar lembaga pendidikan virtual tersebut dapat bertahan lebih lama dan dapat menyikapi kebituah masyarakat dalam hal pendidikan. Dengan berkarirnya lulusan pendidikan bahasa Bahasa Inggris akan lebih dapat berhasil menjadi pengelola karena mereka memiliki dua kompetensi utama yang tidak dimilki oleh tamatan dari program studi lain yaitu kemampuan menagemen dan pembelajaran Bahasa Inggris. Dalam mewujudkan konsep merdeka belajar maka sebelum menamat perkuliahan para mahasiswa dapat mengikuti perkuliaahan pada jurusan managemen, pemasaran ataupun jurusan Informasi dan teknologi.

\section{Public Relation}

Public relation adalah pekerjaann yang bertangguang jawab untuk mengkomunikasikan keberadaan sebuah lembaga atau perusahaan ke masyarakat luas. Apabila skala lembaga ini sudah mencapai cakukapan internasional, maka kemampuan yang mutlak yang harus dimiliki adalah kemampuan berbahasa Inggris. Ini berarti, menduduki posisi public relation pad sebuah lembaga sangat terbuka bagi seorang lulusan Tadris Bahasa Inggris. Sebagai wujud dari merdeka belajar maka sebelum menamatkan perkuliahan para mahasiswa dapat mengikuti perkuliahan pada jurusan Ilmu Komunikasi pada baik di kampus yang sama ataupun di kampus yang berbeda.

\section{Freelance Writer}

Profesi penulis adalah perkerjaan yang sangat menjanjikan baik nasional internasional. Pada skala internasional, tamatanTadris bahasa Inggris sudah memiliki kemampuan menulis yang diharapkan dapat membantu mereka dalam berkarir sebagai penulis. Walaupun sudah dibekali dengan matakuliah writing, akan tetapi untuk menjadi penulis mahasiswa Tadris Bahasa Inggris sangat dianjurkan untuk mengikuti perkuliahan yang dapat membekali mereka dengan kemampuan literature dalam bahasa Inggris. Salah satu dari pr ogram studi yang dimaksud adalah Sastra Inggris yang berada pada pada kampus yang berbeda

\section{ELT Programer/Software Creator}

Menjadi programmer atau pembuat program aplikasi dalam pembelajaran bahasa Inggris adalah sebua profesi baru yang menantang karena pada beberapa tahun belakangan ini pembelajaran bahasa Inggris dengan menggunakan aplikasi sudah menjadi tren di dunia pendidikan. Penerapan proses merdeka belajar dengan mengikuti perkuliahan di program studi mobile application and technology akan menjadikan mahasiswa lebih siap untuk menerapkan disiplin ilmu pengajaran bahasa Inggris menjadi pekerjaan yang lebih bisa menjawan tuntutan masyarakat pada era digital.

\section{ELT Media Animator}

Berbeda dengan ELT programmer, ELT Media Animator adalah profesi yang bertugas untuk membuat gambar dan video visual untuk pengajaran khususnya pembelajaran bahasa Inggris. Dengan menguasai kemapuan desain gambar, grafis dan animasi maka mahasiswa Tadris Bahasa Inggris akan memiliki kemapuan untuk membuat media pembelajaran Bahasa Inggris untuk semua tingkatan. Animated videos can be used for teaching language skills such as writing, listening, reading and speaking. The animated teaching media present audiovisual and moving pictures. The videos represent the technology are used for teaching materials. They should have been modified and adjusted to the learning needs and purposes (Deni,2019).

\section{ELT Material Writer}

Materi ELT Merupakan inti dari proses belajar dan mengajar "sering diumpamakan sebaagai hal paling utama dalam sebuah program" (McDonough et al, 2013: 51) dan didalamnya terdapat sumber input bahasa (Richard,2001). Untuk itu ELT material writer adalah profesi yang masih berkaitan dengan keilmuan pengajaran bahasa Inggris. Pekerja di bidang ini bertugas sebagai penulis atau pembuat materi Pembelajaran Bahasa Inggris yang akan dituangkan dalam bentuk buku, media online, lebaran kerja siswa dan lain- lain. Untuk memiliki kemampuan yang dapat mejawab tantangan pasar kerja maka mahasiswa dapat mengikuti 
magang pada lembaga yang terkait seperti Dinas Pendidikan, LPMP, lembaga TOEFL/ IELTS dan lain lainya.

\section{Online English Teacher}

Pada era Kesuksesan dalam dunia pendidikan seperti pembelajaran online dan Industri 4.0 dan disusul oleh 5.0 teknologi digital merupakan kunci pelaksanaan pendidikan guru dan teknologi adalah factor penentu keberhasilah belajar. merupakan hasil dari perpaduan antara ide baru dan siswa mereka. Siswa memandang guru sebagai wujud nyata dari lembaga dan mata kuliah, merupakan komponen utaman yang dapat menjalankan atau menghancurkan pengalaman belajar yang mereka miliki, ( Freeman, 1997); guru yang peduli pada media online merupakan kunci dari keberterimaan siswa akan teknologi (McPherson \& Nunes, 2004). Profesi lain yang masih bisa menjadi alternatif lulusan Program Studi Tadris Bahasa Inggris adalah guru bahasa Inggris online. Dengan adanya perbedaan proses pembelajaran convesional dan online, maka pencarian metode dan teknik yang cepat akan membatu para guru untuk sukses berkarir dalam bidang ini. Bentuk merdeka belajar yang dapat diikuti adalah dengan mengikuti magang pada lembaga kursus yang sudah terbukti berhasil menerap pembelajaran bahasa Inggris secara online

\section{SIMPULAN}

Kebijakan Merdeka Belajar sudah sepatutnya respon oleh perguruan tinggi agar dapat mndatang kan manfaat luas bagi masyarakat dan perguruan tinggi. Dalam menyikapi kebijakan ini pihak prodi mampu menyikapi, membuat kajian tentang kesiapan dan melakukan studi tentang prospek kerja lulusan. Pada akhirnya, lulusan Tadris Bahasa Inggris memiliki propek kerja yang sangat luas dan masih berkaitan dengan pembelajaran bahasa Inggris yang sesuai dengan tuntutan masyarakat pada masa sekarang.

\section{REFERENSI}

Buku Saku Panduan Merdeka Belajar Kamppus Merdeka. 2020. Direktorate Jendral Perguruan Tinggi. Kementrian Pendidikan Pendidikan danKebudyaan.

Deni, Testiana.2019. Video Animation as Teaching Media in ELT. Prominent journal. Volume 2, Number 2 Freeman, R .1997. Managing Open Systems. London: Kogan Page.

Fridani, Lara. 2009. Inspiring Education: Kisah Inspriratis Pembelajran Anak Usia Sekolah Dasar, Bandung: Alex Media Komputindo.

Language Education in Asia. 2011. Using YouTube in the EFL Classroom Jon Watkins Kwansei Gakuin University. Japan Michael Wilkins Kansai University of International Studies. Volume 2, Issue 1

McPherson, M.A. and Nunes, J.M.B. . 2004 'The role of tutors as an integral part of online learning support', European Journal of Open and Distance Learning. Di Kutip dari http://www.eurodl.org/materials/contrib/2004/Maggie_MsP.html . Diakses 20 Oktober 2020

McDonough, J., Shaw, C. and Masuhara, H.2013. Materials and Methods in ELT. A Teacher's Guide. Third Edition.Oxford: Wiley-Blackwell.

Peraturan Menteri Pendidikan Dan Kebudayaan Republik Indonesia. Nomor 3 Tahun 2020. Tentang Standar Nasional Pendidikan Tinggi

Richards, J. 2001. Curriculum Development in Language Teaching. Cambridge:Cambridge University Press.

Wiliams, Jill.2003.Promoting independent Learning in the Primary classroom. Buckingham: Open University Pres.

Yamin dan Syarif, 2020. Pembangunan Pendidikan Merdeka Belajar (Telaah Metode Pembelajaran) Jurnal Ilmiah Mandala Vol. 6. No. 1. April 2020 